ARQUITETURAS VISÃO. POÉT DO $V E$ AMAZ 


\section{ARQUITETURAS DA VISÃO. POÉTICAS DO 'VER' NA AMAZÔNIA}

\section{E I F G R U N E W A L D}

UNIVERSIDADE FEDERAL FLUMINENSE, BRASIL 


\title{
ARQUITETURAS DA VISÃO: POÉTICAS DO 'VER' NA AMAZÔNIA
}

\author{
Resumo \\ Por este ensaio pretende-se realizar um balanço breve sobre as 'on- \\ tologias da visão' na Amazônia a partir da investigação do tema do \\ xamanismo nos estudos etnográficos sobre os Piro e os Araweté - \\ com fins de mapear a variação das descrições indígenas dos regimes \\ sensoriais amazônicos para aproximá-los, em seguida, das ideias de \\ 'arquitetura da visão' e de 'visão indireta livre', importadas da fi- \\ losofia da diferença de Gilles Deleuze - consideradas ferramentas \\ teóricas importantes para o que se pretende realizar neste trabalho. \\ Palavras-Chave: Amazônia, xamanismo, visão, sentidos.
}

\section{ARCHITECTURES OF VISION: POETICS OF 'SEEING' IN AMAZONIA}

\begin{abstract}
This essay proposes a quick and critical overview of the 'ontologies of seeing' in Amazonia by investigating the Amazonian theme of shamanism, as elaborated in Piro and Araweté ethnographies, to relate it to two concepts of Gilles Deleuze's philosophy, which I consider important theoretical tools in achieving this purpose.
\end{abstract}

Keywords: Amazonia, shamanism, seeing, senses.

\section{ARQUITECTURAS DE LA VISIÓN: POÉTCAS DE 'VER' ENLA AMAZONÍA}

\section{Resumen}

Para este artículo se pretende una breve evaluación de las ontologías de la visión en la Amazonía, departiendo de la investigación sobre el tema del chamanismo en los estudios etnográficos sobre los Piro y Araweté - con el propósito de trazar la variación de las descripciones indígenas de los regímenes sensoriales amazónicos para acercarse, entonces, de las ideas de "arquitectura de la visión " y "visión indirecta libre", importadas de la filosofía de Gilles Deleuze - que se consideran importantes herramientas teóricas para lo que quiero lograr con este trabajo.

Palabras clave: Amazon, el chamanismo, la visión, los sentidos.

Endereço para correspondência: Rua Theófilo Costa 310/803. Jardim Camburi, Vitória - ES. CEP 29092-010. E-mail: leif_grunewald@yahoo.co.uk 
The Seeing Eye

The small dogs look at the big dogs; They observe unwieldy dimensions And curious imperfections of odor. Here is the formal male group: The young men look upon their seniors, They consider the elderly mind And observe its inexplicable correlations. Said Tsin-Tsu:

It is only in small dogs and the young That we find minute observation - Ezra Pound

\section{PRELÚDIO DO VER}

Este ensaio é um desdobramento e uma ampliação de meu primeiro projeto de tese de doutorado sobre as variações nos regimes da percepção sensorial (e, em particular, da visualidade) em diferentes sociocosmologias amazônicas. Seu objetivo é discutir, em particular, sobre a dimensão da visualidade em dois povos amazônicos: os Araweté, um povo falante de uma língua Tupi-Guarani que habita uma única aldeia no curso do médio Ipixuna, um tributário da margem direita do rio Xingu; e os Piro, falantes de uma língua Arawak que habitam as zonas de floresta às margens do baixo rio Urubamba, na Amazônia Peruana; e investigar de que maneira outras dimensões dessas socialidades ameríndias são tributárias dessa dimensão visual, para delinear, finalmente, o esboço de uma teoria ameríndia da visão (ou ainda, mais amplamente, dos sentidos). Com esta proposta, pretendo realizar um balanço abreviado sobre essa literatura procedendo em dois sentidos. Por um lado, devo retornar aos estudos etnográficos sobre os Piro e os Araweté e destacar suas implicações reversas com objetivo de mapear a variação das descrições indígenas dos regimes de visualidade e focalizar, particularmente, uma parte da convergência manifesta em parte dessa literatura. Por outro, almejo realizar um exercício de aproximação do pensamento indígena com as ideias de "arquitetura da visão" e de "visão indireta livre" - sobre as quais argumentou Gilles Deleuze (1990) em seus estudos sobre a imagem cinematográfica - que considero serem ferramentas teóricas estratégicas e importantes para o estudo das 'ontologias da visão' amazônicas.

Pois bem. Mas por que os sentidos e por que, particularmente, a visão? Justamente porque sucede que a visão nos mundos ameríndios (sobretudo naqueles mundos acessados especialmente via xamanismo) não é um modelo de conhecimento que se fundamente pela apreensão de seu objeto à distância (tal como o é para o pensamento Euro-Americano). Como notou oportunamente Tyler (1984), se observaria para o pensamento Ocidental uma hegemonia da visão que implicaria, por seu lado, no esmaecimento da correlação entre o que se vê e o que se diz e na criação de uma predisposição de conceber todo o pensamento e conhecimento como 'visão'. Nesse sentido, o que é dito ser real para o pensamento Euro-Americano seria constituído, portanto, por um modo predominantemente visual de referenciação, em detrimento da veracidade de outros sentidos como a audição, por exemplo. Ora, basta que se veja o que se diz em 
frases como, "só vendo para crer"; ou "eu vi com esses olhos que a terra há de comer" ou mesmo "eu ouvi por aí que..." para denotar incerteza a respeito de alguma coisa ou a improbabilidade de que um evento específico tenha acontecido, donde se poderia sugerir que a visão revelar-se-ia nessa espécie de 'hierarquia cognitiva' como o sentido dominante devido sua habilidade 'mimética', enquanto a audição seria reputada falha e degradada devido ao fato de sua capacidade mimética ser fraca e imperfeita.

Mas isso tudo só de um lado. De outro, se poderia sugerir, tal como destacou Viveiros de Castro (1998), que o pensamento ameríndio sobre a visão a concebe como o modelo perceptivo de conhecimento: não são poucas as línguas indígenas que também efetuam uma distinção entre o conhecimento obtido pela visão (tido então como 'direto') e o conhecimento sobre o qual alguém apenas ouve falar; o discurso xamânico em diversas partes da Amazônia constitui-se a partir de um conjunto de metáforas visuais, bem como o uso de alucinógenos pelos xamãs de alguns povos amazônicos é reputado provocar-lhes deliberadamente uma série de 'visões'; nas socialidades amazônicas em que o corpo de uma pessoa humana é reputado possuir múltiplas almas, não é raro encontrar a descrição de uma alma localizada especificamente nos olhos, dita ser, na maior parte das vezes, a 'alma verdadeira' (é o que logo salta aos olhos, por exemplo, nas etnografias Kaxinawá por Lagrou (2007) e Kensinger (1995); na etnografia Yaminawa por Townsley (1993); na etnografia Waiwai por Mentore (1993)); e também nas etnografias Marubo por Cesarino (2008) e Sharanahua por Déléage (2005)); ou ainda, conforme destacaram Kensinger (ibidem) e Lagrou (ibidem) para a etnografia Kaxinawá, há de notar a centralidade da distinção entre os domínios visíveis e invisíveis na sociocosmologia de alguns povos ameríndios.

Pois bem. Tomada por esse ângulo, a noção indígena de visão parece remeter às noções de ponto de vista e de perspectivismo ameríndio, sobre as quais argumentaram Viveiros de Castro (1996, 1998) e Lima (1996, 2005), mas há de se frisar, entretanto, o seguinte: a proeminência do idioma da visualidade nas descrições sobre o perspectivismo ou sobre a noção indígena de ponto de vista não corresponde a dizer, como notou Viveiros de Castro (op.cit.), que estas se reduzam aos olhos ou ao que se vê através deles. O que se poderia dizer de tudo isso é, no fim, que o perspectivismo ameríndio se serve de diferenças 'perceptuais' a fim de expressar diferenças 'conceituais'. Em poucas palavras, se poderia concluir, seguindo a pista de uma intervenção Viveiros de Castro, que a linguagem epistemológica da visão enquanto forma de conhecimento do mundo estaria, para o pensamento indígena, a serviço de uma ontologia, uma vez, como destacou novamente Viveiros de Castro, o que estaria em jogo para o perspectivismo e para a noção de ponto de vista seria antes a relação entre diferentes ontologias. 
Tais diferenças, mesmo que expressas em termos visuais (o que um jaguar vê difere do que é visto apenas do ponto de vista das pessoas humanas, fazendo com que a própria diferença seja o que habilita um sujeito a enxergar o mundo de uma maneira específica) não são propriamente visuais, mas são, antes, relacionais, pois são menos representações visuais distintas de um mesmo objeto para sujeitos diferentes que relações entre sujeitos dissimilares.

Passemos agora a outro aspecto, relacionado com uma teoria ameríndia da visão ou ainda (mais amplamente), dos sentidos. Passemos precisamente ao que podemos aprender sobre a mesma a partir de uma intervenção de SantosGranero (2006: 62) a respeito da etnografia Yanesha, na qual o autor assinala que as pessoas desse povo consideram que o corpo de uma pessoa humana é dotado de cinco sentidos (a saber: audição, visão, olfato, tato, e paladar) indispensáveis para que um sujeito esteja apto a sobreviver nesse andar do cosmos, añe patsro. Mas, diferentemente do que se observaria para o pensamento Euro-Americano, o pensamento Yanesha reorganiza tal 'hierarquia cognitiva' ao atribuir (a exemplo de variados povos sul-ameríndios) uma importância maior à audição que à visão. Nesse sentido, o privilégio da visão revelado pelo discurso sobre o perspectivismo ameríndio quando colocado ao lado do que argumentou Santos-Granero para os Yanesha, colocaria diante de nós a seguinte questão: seria possível conceber uma perspectiva menos 'olhocentrada' de perspectiva?
Ora, o que não deixa de ser interessante é o fato de que - prolongando a temática da visão tal como desenvolvida nas sociocosmologias ameríndias, talvez se pudesse sugerir ainda que ela (a visão) se desenvolve em continuidade com outros sentidos de um sujeito. É o que argumentou, por exemplo, Jara (1996) a respeito dos cantos dos xamãs Akuriyó; estes são reputados visuais para o xamã, mas são fenômenos auditivos tanto à audiência que os escuta quanto para o doente que está sendo submetido ao tratamento. Além disso, os cantos xamânicos também seriam, segundo Jara, fenômenos materiais: são vistos como flechas para os seres patogênicos desejosos de agredir uma pessoa humana. Ora, mas este seria apenas um lado dessa curiosa continuidade sensorial - a qual chamarei aqui apenas de 'continuidade externa'. Se Jara comentou sobre uma 'continuidade externa', penso que se poderia sugerir, por outro lado, que haveria também uma continuidade sensorial interna, expressa, por exemplo, em variados relatos sobre povos amazônicos Peruanos (Davis e Snell 1968; Cromack 1976; Macera 1999), nos quais são narrados, sobretudo, encontros inesperados entre pessoas humanas e seres não-humanos. Eis o que se descreveu em um relato bastante breve de Davis e Snell (op.cit.: 73) a respeito do encontro entre um homem Matsiguenga e um demônio da floresta (Espanhol, sacha runa. Matsiguenga, kasonkaatini)

"Um homem foi pescar, mas não fisgou nada. Então, desceu rio abaixo e fisgou cinco peixes. De repente, escutou o canto do pás- 
saro do mau-agouro. O homem retornou, passando pela margem do rio e seguiu rio acima. Lá, limpou seus peixes, os colocou em sua bolsa, embrulhou sua rede e voltou para casa. Depois de viajar muito e quando se encontrava subindo o morro que levava para sua roça, de repente viu o demônio sacha runa que descia pelo mesmo caminho. $\mathrm{O}$ sacha runa se atracou com o homem e começaram a lutar. (...) Sua mulher ouviu o ruído que faziam, pois arrancavam arbustos e até mesmo árvores enormes. O homem era muito forte, mas não havia ninguém para ajudá-lo e defendê-lo. Sua mulher escutava que, pouco a pouco, estava perdendo sua força. Em pouco tempo, não o ouviu mais. O demônio o havia vencido". (Davis e Snell 1968: 73, itálicos meus.)

Vê-se, pois, que o que a descrição etnográfica acima visa explicitar é também que toda problemática de relações que envolve uma "cosmopolítica" (Sztutman 2005), provoca um encadeamento de sentidos. Nesse sentido, tudo parece se passar aqui como se as relações que conformam cosmopolíticas contaminassem sucessivamente os sentidos: ver um sujeito não-humano 'contamina', progressivamente, a audição, o paladar, etc. É nesse mesmo sentido que também se poderia sugerir que os olhos são testemunhas daquilo que é trazido à baila e torna-se visível às pessoas humanas - fazendo, como já mencionei acima, da oposição entre visível/invisível algo fundamental nas sociocosmologias de povos das terras baixas da América do Sul. A partir de tudo isso que se disse anteriormente, passemos agora ao mapeamento do tema da visualidade nos materiais etnográficos Piro e Araweté e ao detalhamento das variações das relações de alteridade posta em cena nas descrições indígenas sobre a percepção sensorial. $\mathrm{O}$ fio condutor dessa cartografia do olhar é, pois, o xamanismo e os ditos "conversores ontológicos" (Viveiros de Castro 1986: 533) que estariam estreitamente ligados às mitologias desses povos amazônicos e seriam utilizados pelos xamãs a fim de adquirir uma qualidade 'translúcida' a seus corpos, essencial à prática xamânica tal como caracterizada pelas pessoas desses povos.

\section{ONTOLOGIAS DA VISÃO}

Minha perspectiva se amplia a partir da releitura de dois trabalhos. Um deles é o de Viveiros de Castro (op. cit.) - cujo foco principal é a descrição e uma interpretação da sociocosmologia Araweté a partir dos conceitos ligados à pessoa, à morte, aos deuses, aos mortos, e aos cantos rituais xamanísticos - para propor, então, uma visão da metafísica desse povo capaz de descrever o lugar dos humanos no cosmos e sua inscrição nos elementos que comandam sua ontologia: o da temporalidade e o da diferença. Já o outro é o de Gow (2001) onde o "mundo vivido" dos Piro e as transformações às quais eles foram sujeitos ao longo do curso da história são analisados à luz de um mito específico, pelo qual se narra a história de um homem e de sua viagem ao 'andar de baixo' da terra, habitado pelos queixadas. Não poderia fazer aqui, entretanto, uma 
exposição completa de todos os aspectos complexos dos xamanismos Piro e Araweté, como, por exemplo, todos os aspectos do canto xamanístico Araweté, reputado ser "a área mais complexa da cultura [Araweté]" (Viveiros de Castro 1986:542), ou abordar em sua complexidade a troca de posições de sujeito característica dos cantos xamanísticos Piro (Gow 2001), mas tão-somente destacar alguns aspectos que penso serem importantes para o estudo que pretendo empreender nesse ensaio.

Entre os Piro, não há motivo maior que leve uma pessoa humana a tornarse xamã que o sofrimento, wamonuwata, provocado pela perda trágica e irrecuperável de alguém. Da tragédia, da perda e da impossibilidade de fazer libertar seus afetos, seus pensamentos e sua memória, nshinikanchi do sofrimento provocado pela ausência de um parente morto, há, então, de se encontrar soluções para esta nova condição através do rearranjo das relações com o cosmos, uma vez que, para os Piro, parece não haver outra maneira de 'viver bem', gwashata, que não esteja entrelaçada com o esquecimento daqueles que já se foram. Mas, de fato, o esquecimento não é algo que se consiga facilmente. A melancolia provocada pela perda de um parente pode lançar um Piro ao encontro de duas possibilidades distintas, nas quais o wamonuwata de uma pessoa haverá de ser transformado novamente, por meio da compaixão, getwamonuwata, de seus parentes, em gwashata. De um lado, o sofrimento de uma pessoa pode colocá-la no estado de 'cansado de viver', no qual uma pessoa, como em uma espécie de 'impulso centrífugo', afasta-se do convívio com seus parentes e viaja para áreas distantes da aldeia para viver com outras pessoas. De outro, aquele que sofre da dor causada pela morte pode tornar-se um xamã, a fim de adquirir os poderes e os conhecimentos xamânicos necessários para que possa defender o restante de seus parentes. Tornar-se xamã implica, entretanto, que se abdique (tanto quanto possível), do sexo e do consumo de uma variedade de alimentos; mas, sobretudo, implica também que uma pessoa se 'embriague' cada vez mais de ayahuasca e de toé. Nesse sentido, tornar-se xamã é o mesmo que adquirir progressivamente uma nova 'socialidade' a partir da 'duplicação' da pessoa: ela passa a viver simultaneamente na aldeia com seus parentes e alhures com os 'seres poderosos'. Em resumo, a transformação de uma pessoa em um xamã coincide com a alteração de sua condição ontológica, haja vista que a condição existencial de um xamã não é mais a de humanidade ${ }^{1}$ (Gow 2001: 152).

Pois bem. Se a 'embriaguez' (Piro, gimru) para os Piro corresponde a todos os estados em que há uma ruptura do esquema sensório-motor de uma pessoa (a saber, a embriaguez propriamente dita provocada pelo consumo excessivo de cauim; as intoxicações por tabaco; uma insolação; uma doença que a acometa, etc.), é somente aquela provocada pelo consumo excessivo de ayahuasca e de toé que habilita os xamãs a "ver tudo" (Gow op. cit.: 141). Assim sendo, se poderia sugerir que a ex- 
periência alucinatória provocada pela embriaguez de ayahuasca inaugura uma nova modalidade visual para o xamã, uma vez que se os Piro assumem a aparência de 'outros' absolutamente poderosos (antes, figuravam como grandes e poderosos jaguares. Hoje, como poderosos Brancos) quando em contato com os habitantes de outras aldeias (visto ser esta uma parte essencial do processo contínuo de gwashata), a experiência alucinatória causada pela embriaguez de ayahuasca ou de toé implica, curiosamente, que os 'outros' e/ ou outros lugares sejam vistos sob uma aparência absolutamente exótica. Pois vejamos.

Do ponto de vista daqueles que não beberam ayahuasca, ela não é mais que um cipó. Mas para o xamã Piro 'embriagado' de ayabuasca e dotado, portanto, da capacidade de enxergar todo o mundo a partir de outra modalidade visual que não a dos humanos em condições normais, ela se revela, em um primeiro momento, como uma grande anaconda (o que é seguido, por seu lado, por inúmeras alucinações auditivas). À medida em que a experiência alucinatória prossegue, a ayabuasca revela, então, sua forma verdadeira: ela passa a ser enxergada como uma bela mulher cantando a plenos pulmões. É daí que derivariam (Piro, gyakatya) as imagens alucinatórias do cipó e da anaconda. Nesse sentido se poderia dizer, a exemplo do que argumentou Gow (op. cit.: 142) a respeito das experiências alucinatórias provocadas pela beberagem de ayahuasca, que a forma-cipó e a formaanaconda assumidas pela ayahuasca são produtos do conhecimento da formacorpo de um ser poderoso: a mãe do ayahuasca. Diremos, pois, que há aqui um campo visual basal, uma espécie de plano de imanência visual, dentro do qual as formas-cipó - anaconda e - corpo assumidas pela ayahuasca são apenas modulações diferentes ${ }^{2}$ e contínuas do evento alucinatório. Somos levados a imaginar, portanto, que se há uma modulação fundamental neste plano de imanência visual constituído a partir do olhar sobre a ayahuasca, ela é, certamente, aquela referente à forma-corpo-humana, já que a forma humana (seja ela daqueles que ingeriram ou não ayahuasca) é a referência aperceptiva desse domínio; sendo então a forma-cipó a modulação mais baixa, constituída dentro dos limites do olho humano não investido da ayahuasca.

Mas isso não é tudo. Nesse contexto, a experiência alucinatória de "conversão ontológica" (cf. Viveiros de Castro 1986) provocada pela ayahuasca também põe em cena um acontecimento para os que a ingeriram que difere profundamente do acontecimento posto para aqueles que não a consumiram. Em outras palavras, se poderia sugerir que a experiência com a ayahuasca desdobra-se, no mundo vivido dos Piro, em dois acontecimentos: do ponto de vista dos que não a consumiram, a ayahuasca revela-se apenas em sua forma 'ilusória': a forma-cipó. Mas do ponto de vista daqueles que a ingeriram, a ayabuasca é, inicialmente, uma anaconda que virá a se transformar em uma bela mulher que entoa cantos. Essa maneira de conceber a 'embria- 
guez' provocada pela ingestão de ayahuasca também deixa sua marca na ideia dos Piro sobre os 'seres poderosos': uma entidade que à percepção sensorial normal é invisível e/ou não dotada de forma humana, mas que revela-se como uma pessoa humana e pode ser ouvida cantando. Ora, mas, no fim, a que estaria ligada a qualidade visual ímpar desse novo mundo experienciado pelo xamã? Como dizia Gow (2001: 137) ao comentar sobre esta questão, tal qualidade ímpar está estreitamente ligada à 'marginalidade' ontológica do xamã: é um humano que vive entre duas condições: a de humano e a de Outro.

Quero esclarecer, contudo, que não são apenas os seres não-humanos, revelados posteriormente como humanos aos olhos investidos da ayahuasca, que estão aptos a cantar. Os xamãs Piro também o fazem e cantam o que vêem em sua visão, kayigawlu, donde se poderia argumentar que o canto do xamã não passa de uma descrição desta. Isso de um lado. De outro, conforme ressaltou Gow (op.cit.: 149) a respeito do canto xamanístico Piro, os próprios xamãs sugerem que seus cantos não são mais que imitações do próprio canto da kayigawlu. Mas, no fim, haveria ainda uma terceira possibilidade: as kayigawlu não cantam para o xamã e tampouco são descritas por ele no canto xamanístico (Gow op. cit.: 148). Ao contrário, são produtos da ação, kayagawata, de se fazer enxergar uma visão. $\mathrm{O}$ ponto aqui não é simples, mas se poderia resumir a hipótese assim: as visões do xamã, kayigawlu, são geradas por um kayiglu, um ser poderoso ${ }^{3}$, com fins de criar uma relação de continuidade (ou ainda, uma 'trilha', como argumentou Townsley (1993) acerca do xamanismo Yaminawa) entre eles e constituir, no mesmo movimento, uma espécie de "plano de imanência xamânico" (Viveiros de Castro 2006) no qual o xamã, ao cantar com um kayiglu, assume seu ponto de vista e, do alto de sua nova posição de sujeito, adquire seus poderes. Assim sendo, se poderia concluir que o canto do xamã Piro é um canto de transmutação de perspectivas: ele canta a fim de ver o que o kayiglu vê para, então, realizar a cura xamânica a partir desse novo ponto de vista.

Porém, isso é apenas uma face desse plano de imanência xamânico constituído a partir da troca de ponto de vista do xamã Piro. Assim como notaram Townsley (1993) em seu estudo sobre o canto dos xamãs Yaminawa ${ }^{4}$ e Viveiros de Castro (2006) sobre as mitologias amazônicas, a relação sincrônica que se estabeleceria entre humanos e não-humanos (no caso específico da etnografia Piro, com o kayiglu) e se exprime na transmutação de perspectivas necessária para a ação curativa xamânica realizada pelo xamã Piro possui uma dimensão diacrônica essencial, um passado expresso no mito das mulheres Kochmaloto (ver Gow 2001). Com essa afirmação, se poderia dizer que a posição especial dos xamãs remete à repetição constante do ato que acarretou na mortalidade e na fragilidade das mulheres Kochmaloto: ver outrem com uma forma corporal humana (Gow 2001: 144).

Isso tudo para os Piro. Entre os Arawe- 
té, chama-se o xamã assim: são os Mä̈ de rīpã, suporte para os deuses Mä̈; os Maï dečãka, os videntes dos deuses; os ha'o we mo-ñña hã, aquele que faz cantar as almas, mas também os me'e peyo hã, os benzedores. Pois bem. Como é peculiar à sociedade Araweté, não há ali mulheres-xamãs (são incapazes de controlar a excorporação e seus pescoços são, dizem os Araweté, demasiadamente frágeis para suportar as conversar com os Maï. São, portanto, inaptas para cantar). Se não há mulheres xamãs, isto se dá porque as relações entre homens e deuses são concebidas apenas do ponto de vista masculino. Elas (as mulheres) são, de fato, apenas objetos. "Penhor da aliança, não parte" (Viveiros de Castro 1986: 530), a comida predileta dos deuses.

Aproveito para lembrar também que não há 'iniciação xamânica' entre os Araweté, como tampouco há espíritos familiares do xamã. Mas isso não significa que o xamanismo Araweté se reduza a uma dimensão puramente vocacional. ${ }^{5} \mathrm{O}$ xamã Araweté é um ser que fuma - visto ser o tabaco o emblema e o instrumento de operação do xamã e é um longo ciclo de intoxicações por tabaco que dá 'translucidez', mo-kiyaha, a um homem, isto é, transforma-o em xamã. Ora, mas isso que você relembra - dir-se-ia - redunda no fato de que todos fumam (inclusive as mulheres e as crianças) socialmente entre os Araweté. Sendo assim, só o consumo frequente de tabaco não poderia ser a única condição que diferencia Araweté não-xamã de um homem xamã. Mas há de se notar também, eu retrucaria, que no caso do xamanismo, diferente- mente de todas as outras situações da vida cotidiana Araweté, o xamã fuma sozinho - servido de seu grande charuto de folhas secas de tabaco enroladas em casca de tauari por outro, ao modo do cauim, em um gesto chamado de mo-petemo, que designa, por outro lado, o 'iniciador' do xamã, mo-petemo hã.

Isso apenas de um lado. De outro, se todos fumam, apenas o xamã é dito 'comer' o tabaco, em várias sessões realizadas durante a noite, em completa escuridão, a fim de que o xamã adquira a 'translucidez' necessária para a visão. Não há, entretanto, nenhuma parcimônia nessas 'refeições' de tabaco. São nessas sessões que muitos se embriagam, e desmaiam, 'mortos' pelo tabaco - o que é precedido, ao longo do correr dos charutos, dos sons furiosos $\mathrm{da}$ tosse e do vômito em cascos de jaboti especialmente preparados para isso. Só se cessa, então, a 'alimentação' de tabaco de xamã iniciante, petemo iiaho, isto é, só se para de 'enchê-lo' quando ele desfalece. Ora, se o tabaco 'mata', ele também é, por outro lado, um ressuscitador essencial para despertar falecidos e é sua fumaça que ressucita, segundo os Araweté, os mortos no céu. Nesse sentido, afirmou Viveiros de Castro (op.cit.: 533), "[o tabaco] é um conversor ontológico de 'mão-dupla', efetuando passagens morte-vida, vida-morte, e um transformador natureza-(cultura)-sobrenatureza, como no mito de criação dos animais". Pois bem. Mas como manter-se translúcido? Há de se evitar todas as coisas que 'quebrem a transparência' do xamã iniciante (como, por exemplo, o sexo; 
a carne de tatu-canastra; as comidas estrangeiras como sal, óleo, açúcar; e, especialmente, as frutas cruas) a fim de se manter a 'luminescência' característica de sua pele, atribuída ao tabaco, visto ser este, ao mesmo tempo, 'uma coisa que ilumina', me'e eepe hã, e uma 'coisa de saber', me'e koã hã, que os põe em contato com os Maï.

Mas o tabaco não é o único emblema do xamã Araweté. Ao lado dele, há também o chocalho aray, que não pretendo cartografar aqui, mas tão-somente destacar que ele é reputado ser um instrumento transformador por excelência, utilizado tanto para realizar operações 'terapêuticas' (reassentamento de alma e/ou fechamento do corpo por meio das operações xamânicas de imone), quanto operações "místicas" (Viveiros de Castro 1986: 536), dado seu uso nas cerimônias em que há consumo espiritual de alimentos por parte dos Maï. Dele se diz ser também, como o tabaco, uma 'coisa de saber' e uma 'coisa que ilumina'. Com tais equipamentos, enfim, o xamã Araweté se capacita às operações de cura e de prevenção às quais é frequentemente requisitado: as operações de recondução da alma, imone; o assassinato de espíritos malignos terrestres, $\tilde{A} \tilde{n} \tilde{\imath}$ e seus congêneres, Ayaraetã e Iwikatihã); e a dispersão de flechas alimentares. Assim sendo, ser comedor de fumo e senhor de aray é o que habilita o xamã a ser um suporte dos Maï, que cantam por sua boca. $\mathrm{O}$ canto xamanístico (ou a 'música dos deuses') é, nesse sentido, a atividade mais frequente dos xamãs (não há homem adulto que não tenha cantado ao menos algumas vezes na vida), e, como mencionei anteriormente, a área mais complexa da cultura Araweté: é, a um só tempo, a única fonte de informação sobre o estado do cosmos, sobre a situação dos mortos depois de chegados ao céu. Mais ainda: é “o 'rito' central da vida do grupo" (Viveiros de Castro op. cit.: 542-543).

Mas que se frise, entretanto, o seguinte: as canções, a exemplo do que viu-se para a etnografia Piro, são dos deuses Maï e o xamã não tem controle sobre elas. Quando se trata, então, das canções xamanísticas Araweté, conforme ressalta Viveiros de Castro, tudo se passa como se estas fossem uma 'fanopéia'. Os cantos xamanísticos são, portanto, evocações vívidas (mas elípticas) de situações visuais (ou, mais amplamente, sensoriais). (Viveiros de Castro 1986: 548). Também são muito mais que isso. Se a 'música dos deuses' é a evocação vívida de situações visuais, ela também faz transparecer imagens focais no canto por associação de temas canônicos do discurso sobre o céu. É o que se vê, logo, no canto de Kãñ̃payero, o canto Araweté da 'castanheira emplumada', que traz à baila a imagem focal de uma grande castanheira celeste ornada pelos deuses com as plumas brancas da harpia - criada pelo xamã no canto por meio da associação de dois temas importantes do discurso celeste: as castanheiras e as harpias. Mas isso não é tudo. Se poderia sugerir ainda, por outro lado, que acresce-se ao motivo visual da castanheira emplumada trazido à tona no canto xamanístico um motivo olfativo: as fragrâncias celestes, 
cujo avatar seria a resina perfumada da árvore ičrii (muito utilizada pelas mulheres e pelos quartetos apīhi-pihâ).

Há de se ressaltar, por fim, que a propensão da poesia Araweté para a fanopéia não se encerra no canto do xamã. Esta seria, por outro lado, levada ao máximo nos 'cantares do inimigo', awñ marakã , que dividem o baixo conteúdo informacional com a música xamanística, mas que se distinguem por seu regime enunciativo: as canções do inimigo, tendo ponto de vista invariável (diferentemente das canções do xamã, nas quais as posições enunciativas eram cuidadosamente especificadas mediante o procedimento citacional ou a pragmática do sistema de vozes), são sempre cantadas do ponto de vista do inimigo, isto é, o inimigo é o sujeito do enunciado atualizado pelo canto do matador (Viveiros de Castro 1986: 586).

Pois bem. Os fatos das etnografias Piro e Araweté evocam diretamente as noções de "arquitetura da visão" e de "visão indireta livre", com que Deleuze (2007 [1990]) argumentou em favor de um 'novo perspectivismo' que seria capaz de oferecer meios para estabelecer uma verdadeira progressão nas figuras descritas enquanto conexões de projeções ou ainda, como destacou elegantemente o autor, a "série de suas próprias metamorfoses". É nesse contexto que eu situaria, portanto, uma 'ontologia da visão'. Passamos assim a ele.

\section{ARQUITETURAS DA VISÃO}

No Imagem-Tempo (1990) - segundo livro de Gilles Deleuze sobre os con- ceitos que o cinema é capaz de suscitar e as relações que estes conceitos podem estabelecer com outros conceitos e outras práticas (não tendo a prática dos conceitos em geral nenhum privilégio sobre as demais) - Deleuze derruba de vez o pilar central dos estudos teóricos sobre o cinema, a saber, a concepção de que o cinema é uma língua (universal ou primitiva [ou mesmo uma linguagem]) semioticamente (ou semiologicamente) interpretável, substituindo-o pela ideia de que o cinema traz à luz uma espécie de matéria inteligível, um correlato necessário por meio do qual a linguagem constrói seus próprios objetos. Mais ainda: esse 'correlato necessário’ consiste, por seu lado, em um conjunto de processos de pensamento (imagens pré-linguísticas) e de pontos de vista tomados sobre esses movimentos (signos pré-significantes). Em suma, o cinema seria um sistema de imagens e signos pré-linguísticos em que se poderia distinguir dois tipos de imagens e seus signos correspondentes: as imagens-tempo e as imagensmovimento.

Ao longo das páginas do livro, essa tese sustenta-se de um vasto sobrevôo sobre a produção cinematográfica - o qual, quando pintado em um dos capítulos centrais em que o autor argumentará sobre as 'potências do falso', traz à tona um conceito importante para o leitor-etnólogo: o de perspectivismo. Em uma abordagem mais localizada ou atenciosa para com o conceito de perspectivismo tal como evocado por Gilles Deleuze em uma observação sobre o cinema de Orson Welles e a 
transformação do pensamento produzida pelo Barroco, o que se observa é que este conceito não se define nem por uma conservação do ideal de verdade, nem pela variação de pontos de vista exteriores sobre um objeto que se suporia invariável. A perspectiva não sendo mais nem verdade, nem aparência, faz com que no perspectivismo o ponto de vista seja constante, mas sempre interno aos objetos, que passam a se apresentar, então, como a metamorfose de uma única coisa em devir. Além disso, o próprio objeto não passa mais, em última instância, da conexão de suas próprias metamorfoses. E o é justamente porque, como ressaltou Deleuze (1990: 175), “as perspectivas ou projeções são o que não é nem verdade, nem aparência".

No entanto, conforme também tentou mostrar Deleuze, sucede que para que o perspectivismo ofereça meios para estabelecer uma verdadeira progressão dessas figuras, seria preciso acrescentar-lhe uma 'teoria das sombras' que se conceberia, portanto, como a inversão de uma geometria projetiva - visto que se nesta o 'olho' instalava-se no ápice do cone e nos dava projeções tão variáveis dos planos de secção, círculo, elipse, ponto, reta, parábola, hipérbole, etc. (o que faria de um objeto, em última instância, a conexão destas projeções), na teoria das sombras o olho abandona o ápice do cone e seu lugar passa a ser ocupado pela fonte luminosa, forçando as projeções a se fazerem por 'zonas de sombras' (Deleuze op. cit.: 175-176). É, então, do acréscimo de uma 'teoria das sombras' ao perspec- tivismo que se formaria a 'arquitetura da visão', capaz de impor à perspectiva uma dupla transformação: um 'centro' perceptivo que seja, ao mesmo tempo, ótico e luminoso, conjugando, assim, "a descritiva ou projetiva, e a narrativa ou tenebrosa" (Deleuze op. cit.: 176).

Podemos, entretanto, abrir aqui um parênteses para constatar que a questão do perspectivismo colocada nesses termos acaba por ressoar na ideia de perspectivismo ameríndio, cujo estímulo maior, como vimos anteriormente, seria a ideia indígena segundo a qual a maneira como os humanos vêem os animais, os deuses, os espíritos, as plantas, os objetos, as formas de relevo, os fenômenos meteorológicos, etc. diverge profundamente da maneira que os centros de agência não-humanos vêem a si próprios e os humanos. Voltemos a uma ideia fundamental do perspectivismo ameríndio, sobre a qual Viveiros de Castro (1996: 128) escreveu o seguinte:

"Ser capaz de ocupar o ponto de vista é sem dúvida uma potência da alma, e os não-humanos são sujeitos na medida em que têm (ou são) um espírito; mas a diferença entre os pontos de vista (e um ponto de vista não é senão diferença) não está na alma, pois esta, formalmente idêntica através das espécies, só enxerga a mesma coisa em toda parte - a diferença é dada pela especificidade dos corpos. Isso permite responder às perguntas: se os não-humanos são pessoas e têm almas, em que se distinguem dos humanos? E por que, sendo gente, não nos vêem como gente?” 
Decorre dessa observação do autor sobre a ideia de perspectivismo que esta possui duas faces distintas. Uma delas, de generalidade e outra de especificidade. Haveria de existir aqui, segundo o autor, também uma espécie de condição virtual que interligaria os humanos e os centros de agência não-humanos e definiria a possibilidade de cada um desses seres ocupar um determinado ponto de vista. Ora, é, então, a alma quem assume o papel de condição virtual que interliga subjetividades distintas. Isso de um lado. De outro, se poderia argumentar que a problemática do perspectivismo indígena faz referência a uma "variação contínua entre signos e coisas", cabendo, portanto, à diferença corporal entre centros de agência distintos provocar tal variação na forma como os sujeitos apreendem uma mesma coisa; caso contrário, todos os seres enxergariam as mesmas coisas da mesma maneira.

Teríamos assim, de um lado, o perspectivismo, cujo 'centro' é ocupado pelo 'olho' de um sujeito/objeto específico, ou a centralidade do ponto de vista, interno a cada sujeito e variável pela diferença externa/corporal entre eles e, de outro, a carência de uma "teoria das sombras" (pelo menos para o perspectivismo tal como discutido por Deleuze (1990: 175), que retiraria o 'olho' (ou o ponto de vista) do 'centro', substituindo-o pela fonte luminosa, forçando as projeções a não mais se fazerem a partir de um ponto de vista específico, mas sim por zonas de sombras, determinadas a partir da luz lançada por outrem. À luz dessa distin- ção, podemos, portanto, indagar agora: que seria, então, uma teoria das sombras que, acrescida ao perspectivismo ameríndio, comporia a arquitetura da visão indígena e imporia a ela uma dupla transformação? Tal questão ainda permanece um pouco obscura para mim. Contudo, minha hipótese construída a partir das etnografias Piro e Araweté é esta: são os conversores ontológicos, reputados provocar visões ao 'iluminar' os olhos dos xamãs, que ocupam nos exemplos ameríndios a posição de 'fonte luminosa' que, ao substituir o 'olho natural' do xamã pelo ponto de vista de outrem, força o que é visto normalmente a ser enxergado a partir da luz lançada por outrem. Ora, mas isso não é tudo. Penso que poderíamos argumentar ainda que se esses dois aspectos fundamentam, em certa medida, uma teoria etnográfica sobre a visão, também se poderia propor, a partir da transmutação de perspectivas expressa no sistema dos xamanismos Piro e Araweté, uma teoria etnográfica sobre o acontecimento e sobre sua contra-efetuação, inspirados no conceito de Gilles Deleuze (1990) de "visão indireta livre". Vejamos, pois, mais de perto.

Disse acima que os xamanismos Piro e Araweté se efetuam a partir da transformação do ponto de vista do xamã provocada pelo uso da ayahuasca ou do toé (no caso Piro), ou do tabaco e o chocalho aray (quando se trata do xamanismo Araweté) que reduziria, por seu lado, a assimetria entre os humanos e os deuses/seres poderosos. Assim sendo, se poderia sugerir que o 
canto xamanístico atualiza através de imagens focais construídas a partir da associação de temas canônicos do discurso celeste (é lá que moram os Mä̈ Araweté, por exemplo) uma série composta por situações visuais (ou, mais amplamente, sensoriais), bem como se poderia argumentar também que a palavra cantada do xamã humano é índice de seu ponto de vista transmutado no ponto de vista não-humano. Pareceme, porém, que uma reformulação bastante razoável seria reorganizar esta afirmação em três pontos complementares. Primeiramente, penso que o que a situação visual enxergada/evocada pelo xamã configura é a passagem da linha espaço-temporal ${ }^{8}$ comportada por seu tipo específico de olho àquela comportada pelos olhos dos deuses/ seres poderosos. Além disso, não é menos notável o fato de que o olhar de outrem opera como uma espécie de 'substancializador' de corpos. Em segundo lugar, a palavra cantada pelo xamã faz existir, nesse sentido, pelo menos duas linhas espaço-temporais distintas - fazendo do xamã-cantador (aquele que 'torce' em música a sua visão) um sujeito disperso nessas linhas.

Por fim, o terceiro ponto é o destaque à ideia de que os pontos de vista e suas transmutações provocadas pelos conversores ontológicos (tomados como uma espécie de 'lanterna' que 'ilumina' os olhos do xamã e clareia sua visão) quando colocados ao lado da ideia de 'arquitetura da visão' nos permitem sugerir que uma 'arquitetura da visão’ ameríndia delineia dois planos de imanência superpostos e mutuamente implicados. Um deles é o plano de imanência sensorial do xamã construído a partir da transmutação de sua perspectiva, uma imagem de seu pensamento sensorial expressa no canto quando em relação com formas não humanas de alteridade. Nele, então, a visão dos deuses acarreta na audição do xamã, que acarreta na sua visão e em sua fala que irá acarretar, novamente, na audição de outrem. É importante, entretanto, que não se confunda aqui, como notou Deleuze (1991) o plano de imanência com os conceitos que o ocupam, pois os mesmos conceitos (a visão, particularmente), podem aparecer mais de uma vez nesse plano de maneira distinta. Logo, um sentido é uma 'intensidade', um corte, ou uma posição diferencial nesse plano. São, pois, ao mesmo tempo, tanto o próprio conceito quanto a sua própria variação (cf. Deleuze op. cit.: 42), transformando, nesse mesmo movimento, o plano de imanência sensorial no espaço de 'diagramação' dessas intensidades.

Ora, mas há de se notar, por fim, que essa ideia nos lança ao encontro do plano de imanência visual cuja existência apenas mencionei acima e que, aos meus olhos, estaria superposto e mutuamente implicado a esse primeiro plano. Este é, portanto, um esquema de "visão indireta livre" (a palavra está em Deleuze 1990: 221), no qual tudo o que é visto vai do xamã aos seres poderosos/deuses, quer o xamã se expresse pela intercessão de uma personagem autônoma, independente do autor e de qualquer papel fixado por ele (vale lembrar que nos Araweté a maioria dos 
homens cantam e nos Piro a maioria dos homens bebem ayahuasca), quer o xamã aja e fale como se seus próprios gestos e palavras já fossem reportados por um terceiro. Assim sendo, se essa afirmação me permite continuar, penso que o que esse plano visual indireto livre coloca em xeque é a redundância do sujeito da fórmula $\mathrm{Eu}=\mathrm{Eu}$, ao revertê-la em outra fórmula: Eu=Outro. O que está em jogo aqui é, então, que o jogo de imagens visuais constituído a partir da relação entre o que é visto por um xamã e entoado em seu canto e o que é visto a partir do ponto de vista de outrem é, de certa maneira, serial e 'atonal' (se me permitem o uso da palavra), visto que cada série exprime a maneira pela qual um sujeito se exprime indiretamente numa sequência de imagens atribuíveis a outro, ou, inversamente, a maneira pela qual um sujeito se exprime indiretamente na visão de um sujeito considerado como outro. Seja como for, a unidade do autor é rompida em favor do discurso da diversidade, da deformidade e, sobretudo, da alteridade.

\section{NOTAS}

${ }^{1}$ Os xamãs distinguem-se, dizem os Piro, do restante da humanidade por conseguirem entrar no céu e transformarem-se em jaguares (Ver Gow 2001: 152).

2 Ver Viveiros de Castro (2006).

${ }^{3} \mathrm{O}$ que não deixa de ser curioso é que o kayig$l u$, apesar de provocar visões, não tem forma visual, mas apenas uma forma aural. O que compõe o seu corpo são apenas canções e conhecimento (ver Gow 2001:148).
${ }^{4}$ Note-se que os Yaminawa são reputados 'indios bravos' pelos Piro do baixo rio Urubamba, a ponto destes repreenderem seus filhos gritando-lhes: 'Yaminawa!' (ver Gow 1991:6).

${ }^{5}$ Ainda que os sonhos com jaguares e com a Coisa-Onça celestes sejam tomados pelos Araweté como índice de alguma vocação xamânica (ver Viveiros de Castro 1986: 531).

${ }^{6}$ Fanopéia é um conceito criado por Ezra Pound, para referir-se à matéria visual de um poema. É o conjunto de técnicas aplicadas para criar imagens que afetam a imaginação visual. A fanopéia configuraria, portanto, o poema no espaço físico e imaginário, mas o faz (curiosamente) transpor fronteiras (ver Pound 2006).

${ }^{7}$ Note-se que ao colocar-se por detrás de qualquer forma de 'dizer-eu' (que, como mencionei acima, só se dá a partir de um corpo), a alma generaliza a condição de sujeito às espécies que a possuem, ao dotarlhes de "faculdades que são ao mesmo tempo psicológicas, sociológicas e intelectuais como: consciência de si e de outrem, linguagem, pensamento, socialidade" (Lima 2002:5). Também quero registrar que todo o comentário sobre o perspectivismo indígena é auto-canibalizado (com pequenas modificações) de um trecho da dissertação de mestrado que concluí recentemente.

${ }^{8}$ Para um comentário bastante elegante sobre o conceito de ponto de vista e um 'tempo bilinear múltiplo', ver a intervenção importante de Lima (1996).

\section{REFERÊNCIAS}

Cesarino, P. N. 2008. Oniska: a poética da morte e do mundo entre os Marubo da Amazốnia Ocidental. Tese de Doutorado. Departamento de Antropologia Social, Universidade Federal do Rio de Janeiro. 
Cromack, G. 1976. Narraciones Cashinabuas sobre Espiritus y su Contexto Cultural. Lima: Ministerio de Educación.

Davis, H. e B. E. Snell. 1968. Kenkitsatagantsi Matsigenka: Cuentos Folklóricos de los Machiguenga. Lima: Ministerio de Educación.

Deleuze, G. 1990. A Imagem-Tempo. São Paulo: Brasiliense. 1991. Qu'est ce que la philosophie. Paris: Les Éditions de Minuit.

Déléage, P. 2005. Le chamanisme Sharanahua: Enquête sur l'apprentissage et l'épistémologie d'un rituel. Thèse de Doctorat. École des Hautes Études en Science Sociales, Paris.

Gow, P. 2001. An Amazonian myth and its history. Oxford: Oxford University Press. 1991. Of mixed blood: Kinship and history in Peruvian Amazonia. Oxford: Clarendon Press.

Jara, F. 1996. El camino del kumu: Ecología y ritual entre los Akuriyó de Surinam. Quito: Abya-Yala.

Kensinger, K. 1995. How real people ought to live: the Cashinahua of Eastern Peru. Prospect Heights: Waveland Press.

Lagrou, E. 2007. A fluidez da forma: arte, alteridade e agência em uma sociedade amazônica (Kaxinawa, Acre). Rio de Janeiro: TopBooks.

Lima, T. S. 1996. O dois e seu múltiplo: reflexões sobre o perspectivismo em uma cosmologia Tupi. Mana 2(2): 21-47.

. 2005. Um peixe olhou para mim. São Paulo: Editora UNESP.

Macera. 1999. Llanchama: Cuentos Pintados/ Amazonía. Lima: Ministerio de Educación.

Mentore, G. 1993. Tempering the social self: Body adornment, vital substance, and knowledge among the Waiwai. Journal of Archaeology and Anthropology 9: 22-34.
Pound, E. 2006. Abc da Literatura. São Paulo: Cultrix.

Sztutman, R. 2005. O profeta e o principal. A ação politica ameríndia e seus personagens. Tese de Doutorado. Departamento de Antropologia, Universidade de São Paulo, São Paulo.

Santos-Granero, F. 2006. Sensual vitalities: Noncorporeal modes of sensing and knowing in native Amazonia. Tipití 4:1. 57-80.

Tyler, S. A. 1984. The vision quest in the west or what the mind's eye sees. Journal of Anthropological Research 40(1): 23-40

Townsley, G. 1993. Song paths: The way and means of Yaminahua shamanic knowledge. L'homme 33: 126-128; 449-468.

Viveiros de Castro, E. 1986. Araweté: os deuses canibais. Rio de Janeiro: Jorge Zahar. . 1996. Pronomes cosmológicos e o perspectivismo ameríndio. Mana. 2(2): 115-144.

1998. Cosmological perspectivism in Amazonia and elsewhere. Cambridge: $\mathrm{S}$. Bolívar lectures. MS, 1-100. .2006. A floresta de cristal. Cadernos de Campo 14-15: 319-338.

Recebido em 12/02/2012.

Aprovado em 24/11/2012. 